\title{
Why Multi Target Neuroprotective-Neurorestorative Drugs for Neurodegenerative Diseases
}

\author{
Moussa B H Youdim* \\ Department of Familty of Medicine, McGill University, Israel
}

Submission: January 12,2018; Published: August 02,2018

*Corresponding author: Moussa B H Youdim, Department of Familty of Medicine, Technion-Rappaport Familty Faculty of Medicine, McGill University, Haifa, Israel; Email: youdim@technion.ac.il

Keywords: Parkinson's disease; Drug candidates; Monoamine oxidase; Disorders; Pathology; Accumulation; Glutaminergic excitotoxicity; Neurobiology; Ceruloplasmin; Phenomena; Lactacystin; Mitochondria; Streptocozin; Iron; Animal; Penicillamine; Scavengers; Oxidative stress

Abbreviations: PD: Parkinson's disease; AD: Alzheimer's disease; ALS: Amyotrophic Lateral Sclerosis; MAO: Monoamine Oxidase; APP: Amyloid Precursor Protein; STZ: Strep Toco Zin

\section{Introduction}

Novel therapeutic approaches for the treatment of Parkinson's disease (PD) and Alzheimer's disease (AD) comprise of drug candidates designed specifically to act on multiple CNS targets rather than a single "receptor" symptomatic site as has been done with monoamine oxidase or cholinesterase inhibitors respectively for these disorders. One major pathology of PD and $\mathrm{AD}$ is the accumulation of iron in substantia nigra pars compacta, nucleus of PD, nucleus basilus, dentate gyrus, amyloid plaques, and tangles of AD. The iron is thought to contribute the onset of oxidative stress and glutaminergic excitotoxicity associated with these disorders [1].

The accumulation of transition metals, specially iron and the dysregulation of its metabolism are a hallmark in the pathogenesis of almost all sporadic and familiar neurodegenerative diseases including Parkinson's disease (PD), Alzheimer's disease (AD) Amyotrophic Lateral Sclerosis (ALS) Huntington disease, Fredrich ataxia, ceruloplasmin, PANK2 [1]. Indeed, for some unexplained reason iron accumulates at brain regions where neurons are degenerating and also progressively accumulates in the brain during normal aging, together with increased activity of hydrogen peroxide producing mitochondrial monoamine oxidase. In this connection, metallo neurobiology has become extremely important in establishing the role of iron in the onset and progression of neurodegenerative diseases. Neurons have developed several protective mechanisms against oxidative stress, among them, the activation of cellular signaling pathways. The final response will depend on the identity, intensity, and persistence of the oxidative insult.

The characterization of the mechanisms mediating the effects of iron-induced increase in neuronal dysfunction and death is central to understanding the pathology of a number of neurodegenerative disorders and to develop disease modifying neuroprotective-neurorestorative drug. What is most curious is that a similar phenomenon of iron accumulation occurs in the exactly the same brain regions in animal models of PD and AD. Our group was the first to show that nutrition iron deficiency or desferal and other iron chelators pretreatment were neuroprotective in the classical animal models of PD, such 6-hydroxydopamine, MPTP and ubiquitin inhibitor lactacystin [2]. However, copper the chelator, D-penicillamine was neuroprotective [3]. The poor brain permeability of desferal led us to develop novel brain permeable iron chelators-radical scavengers and we were able to develop several multi target derivatives from the iron chrealtors possessing monoamine oxidase and cholinesterase inhibitor moieties as prodrugs in animal models of PD, AD, and ALS.

It is well recognized that the process of neurodegeneration in PD and AD is multi factorial cascade of events. These include, oxidative stress, glutaminergic excitotoxicity, mitochondria dysfunction, nitric oxide, inflammation, proteasome ubiquitin collapse, and decline of neurotrophic factors. We were the first to suggest development of multi target drugs for neurodegenerative diseases [4] and we have synthesized several multi target non-toxic, brain permeable iron chelator drugs, M-30 series, possessing propargyl Monoamine Oxidase (MAO) and cholinesterase inhibitor moieties, with neuroprotective and neurorestorative activities and iron-chelating component, from our prototype iron chelator VK-28. M-30 and its derivatives such as HLA-20, were shown to possess a wide range of pharmacological activities, including pro-survival neurorescue effects, induction of neuronal differentiation and regulation of 


\section{Open Access Journal of Neurology \& Neurosurgery}

Amyloid Precursor Protein (APP) and $\beta$-amyloid $(A \beta)$ levels [58].

M-30 was found to decrease apoptosis of SH-SY5Y neuroblastoma cells in a neurorescue serum deprivation model, via reduction of the pro-apoptotic proteins Bad and Bax, and inhibition of the apoptosis-associated phosphorylated H2A.X protein (Ser 139) and caspase 3 activation. In addition, M-30 and its derivatives induced the outgrowth of neurites, triggered cell cycle arrest in G0/G1 phase and enhanced the expression of growth associated protein-43, HIF (Hypoxia Inducing Factor) and the neurotrophins, BDNF, GDNF VGEF and erythropoietin $[9,10]$ This has been shown to be associated with the inhibition of iron dependent prolyl-4-hydroxylase that regulates HIF. These compounds have the ablity of converting more than $85 \%$ of adult human stem cells in culture into neurons. Furthermore, since APP has been shown to be an iron regulated protein, similar to ferritin, by possessing 5" UTR in its mRNA element, M-30 and its derivatives markedly reduced the levels of cellular APP and $\beta$-Cterminal fragment ( $\beta$-CTF) and the levels of the amyloidogenic $\mathrm{A} \beta$ peptide in the medium of SH-SY5Y cells and Chinese hamster ovary cells stably transfected with the APP 'Swedish' mutation. As a consequence, levels of the non-amyloidogenic soluble $\mathrm{APP} \alpha$ and $\alpha$-CTF in the medium and cell lysate respectively were coordinately increased via activation of $\alpha$-secretase. This process was prevented by $\alpha$-secretase and PKC inhibitors. Both M30 and HLA-20 have neurorestorative activity in in vivo models of Parkinson's disease, 6-hydroxydoapminr, MPTP and ubiquitin inhibitor, lactacystin and restore the cognitive deficit in the APP/PS1 Tg mice, Strep Toco Zin (STZ) model of AD and rat Tg model of AD [11]. These properties, together with their iron chelating, cholinesterase and brain selective MAO inhibitory activities and propargylamine dependent neuroprotective and neurorestorative effects, suggest that these drugs might serve as an ideal drug for $\mathrm{PD}$ and $\mathrm{AD}$, without resorting to inhibition of $\beta$-secretase, in which oxidative stress and iron dysregulation have been implicated [12-14].

\section{References}

1. Zecca L, Youdim MB, Riederer P, Connor JR, Crichton RR (2004) Iron, brain ageing and neurodegenerative disorders. Nat Rev Neurosci 5(11): 863-873.

2. Ben-Shachar D, Eshel G, Finberg JP, Youdim MB (1991) The iron chelator desferrioxamine (Desferal) retards 6-hydroxydopamineinduced degeneration of nigrostriatal dopamine neurons J Neurochem 56(4): 1441-1444.

3. Youdim MB, Grünblatt E, Mandel S (2007) The copper chelator D-penicillamine, does not attenuate MPTP induced dopamine depletion in mice. J Neural Transm (Vienna) 114(2): 205-209.

4. Youdim MB, Buccafusco JJ (2005) Multi-functional drugs for various CNS targets in the treatment of neurodegenerative disorders. Trends in Pharmacological Science 26(1): 27-35.

5. Weinreb O, Amit T, Mandel S, Kupershmidt L, Youdim MB (2010) Neuroprotective multifunctional iron chelators: from redox-sensitive process to novel therapeutic opportunities. Antioxid Redox Signal 13(6): 919-949.

6. Zheng H, Fridkin M, Youdim MB (2012) From antioxidant chelators to site-activated multi-target chelators targeting hypoxia inducing factor, beta-amyloid, acetylcholinesterase and monoamine oxidase A/B. Mini Rev Med Chem 12(5): 364-370.

7. Liu W, Lang M, Youdim MBH, Amit T, Sun Y, et al. (2016) Design, synthesis and evaluation of novel dual monoamine-cholinesterase inhibitors as potential treatment for Alzheimer's disease. Neuropharmacology 109:376-385.

8. Kupershmidt L, Amit T, Bar-Am O, Youdim MB, Weinreb O (2012) The novel multi-target iron chelating-radical scavenging compound M30 possesses beneficial effects on major hallmarks of Alzheimer's disease. Antioxid Redox Signal 17(6): 860-877.

9. Kupershmidt L, Weinreb O, Amit T, Mandel S, Bar-Am O, et al. (2011) Novel molecular targets of the neuroprotective/neurorescue multimodal iron chelating drug M30 in the mouse brain. Neuroscience 189: $345-58$

10. Weinreb O, Amit T, Bar-Am O, Youdim MB (2016) Neuroprotective effects of multifaceted hybrid agents targeting MAO, cholinesterase, iron and $\beta$-amyloid in ageing and Alzheimer's disease. $\mathrm{Br} \mathrm{J}$ Pharmacol. 173(13): 2060-2094.

11. Pimentel LS, Allard S, Do Carmo S, Weinreb O, Danik M, et al. (2015) The Multi-Target Drug M30 Shows Pro-Cognitive and Anti-Inflammatory Effects in a Rat Model of Alzheimer's Disease. J Alzheimers Dis 47(2): 373-383.

12. Youdim MB, Oh YJ (2013) Promise of neurorestoration and mitochondrial biogenesis in Parkinson's disease with multi target drugs: an alternative to stem cell therapy. Exp Neurobiol 22(3): 1671672.

13. Youdim MB (2013) Multi target neuroprotective and neurorestorative anti-Parkinson and anti-Alzheimer drugs ladostigil and m30 derived from rasagiline Exp Neurobiol 22(1): 1-10.

14. Geldenhuys WJ, Van der Schyf CJ (2013) Rationally designed multitargeted agents against neurodegenerative diseases. Curr Med Chem 20(13): 1662-1672.

\begin{tabular}{l} 
Your next submission with Juniper Publishers \\
will reach you the below assets \\
- Quality Editorial service \\
- Swift Peer Review \\
- Reprints availability \\
- E-prints Service \\
- Manuscript Podcast for convenient understanding \\
- Global attainment for your research \\
- Manuscript accessibility in different formats \\
( Pdf, E-pub, Full Text, Audio) \\
- Unceasing customer service \\
Track the below URL for one-step submission \\
https://juniperpublishers.com/online-submission.php \\
\hline
\end{tabular}


